\title{
The Dutch Lower Extremity Functional Scale was highly reliable, valid and responsive in individuals with hip/knee osteoarthritis: a validation study
}

\author{
Thomas J Hoogeboom 1,2,3* Rob A de Bie ${ }^{2,3}$, Alfons A den Broeder ${ }^{2}$ and Cornelia HM van den Ende ${ }^{2}$
}

\begin{abstract}
Background: The WOMAC is the most widely used self-report measure to evaluate physical functioning in hip or knee osteoarthritis, however its ability to discriminate pain and physical functioning (i.e. discriminate validity) has repeatedly been questioned. Little to no data is available on the discriminant validity of alternative questionnaires that measure the same construct, for instance the Hip and Knee Osteoarthritis Outcome Score (HOOS and KOOS, respectively) and the Lower Extremity Function Scale (LEFS). Therefore, we translated the LEFS to Dutch and studied its psychometric properties (i.e. validity, reliability and responsiveness). In addition, we assessed the discriminate validity of the LEFS, HOOS and KOOS.

Methods: After translation with a forward/backward protocol, 401 individuals with hip or knee osteoarthritis completed the LEFS, HOOS/KOOS, SF-36, Hospital Anxiety and Depression Scale and Checklist Individual Strength questionnaires. To assess reliability and responsiveness, a sample of 106 and 108 patients completed a comparable set of questionnaires within 3 weeks and 3 months, respectively. Feasibility, validity, reliability and responsiveness were evaluated. Discriminant validity of the LEFS, HOOS and KOOS was examined by contrasting the scales' correlations with the physical functioning subscale of the SF-36 with the scales' correlations with the bodily pain subscale of the SF-36.
\end{abstract}

Results: The Dutch version of the LEFS was feasible, had good internal consistency (0.96), good reliability (ICC =0.86), good construct and discriminant validity, and showed no floor or ceiling effects. The minimal detectable change $\left(M C_{90}\right)$ was ten points. Area under the receiver operating characteristic curve (AUC) analyses revealed good ( $A \cup C=0.76)$ and fair $(A \cup C=0.63)$ responsiveness for the LEFS in improved and worsened patients, respectively. Discriminant validity for pain was apparent for the LEFS $(p<0.01)$, but not for the HOOS and KOOS ( $p=0.21$ and $p=0.20$, respectively).

Conclusions: Considering the LEFS' good psychometric qualities and ability to discriminate between pain and functioning, we recommend the LEFS as the outcome measure of choice to assess self-reported physical functioning in individuals with hip or knee osteoarthritis.

\footnotetext{
* Correspondence: t.hoogeboom@maartenskliniek.nl

${ }^{1}$ Department of Rheumatology, Sint Maartenskliniek, PO Box 9011, Nijmegen

6500 GM, The Netherlands

${ }^{2}$ Caphri Research School, Maastricht University Medical Centre, Maastricht,

The Netherlands

Full list of author information is available at the end of the article
} 


\section{Background}

Numerous self-report measures on physical function are available for the evaluation of patients with hip or knee osteoarthritis [1]. Among those, the licensed for use Western Ontario and McMaster University Osteoarthritis Index (WOMAC) [2] is the most widely used [3]. It is recommended by the Osteoarthritis Research Society for use in clinical trials in patients with hip or knee osteoarthritis to measure pain and disability [4]. However, consensus statements consistently advocate that pain and physical function must be measured independently [3,5]. A solid body of evidence demonstrates that the WOMAC-PF (Physical Function subscale) is unable to discriminate between pain and function [6-9].

Recently, three new license free self-report measures to determine functioning in patients with osteoarthritis have become available; the Hip Osteoarthritis Outcome Score (HOOS) [10], the Knee Osteoarthritis Outcome Score (KOOS) [11] and the Lower Extremity Function Scale (LEFS) [12]. One of those new measures, the LEFS, showed promise as a competitive alternative to the WOMAC-PF, as the LEFS can differentiate pain and functioning [13] and detect changes in functional status in the period immediately following surgery [14]. Moreover, the LEFS has excellent test-retest reliability, internal consistency and construct validity $[12,13,15]$. To date, it remains to be seen, whether the physical function scales of the HOOS and KOOS can discriminate between pain and physical function $[10,11,16]$.

Since the LEFS is currently not available in Dutch, the primary purpose of this study was to evaluate the psychometric qualities of the Dutch LEFS in people with hip or knee osteoarthritis. Our secondary objective was to assess the discriminant validity for pain of the physical function subscale of the HOOS and KOOS and the LEFS.

\section{Methods}

First the English version of the LEFS was translated into Dutch according to a standardized procedure described by Beaton et al. [17], and secondly it was tested for psychometric quality by use of prospective data.

\section{Procedure of translation}

The translation procedure consisted of four steps. First, two persons translated independently of each other the English version of the LEFS into Dutch (forward translation) (T1 \& T2); one translator (TJH) had a medical background and was familiar with the concepts of the questionnaire and the other ( $\mathrm{VvS}$ ) was a certified translator without a medical background. Both were native speakers. Based on a consensus meeting one final version (T-12) was formed. Second, two bilingual persons (T3 \& T4) translated the T-12 questionnaire back into English (BT1 \& BT2), to guarantee a consistent translation of the questionnaire. Both translators (PA \& DKJ) were unfamiliar with the original questionnaire, the concepts of the questionnaire, and had no medical background. DKJ is also a certified translator. Third, an expert meeting was organised in which all translators, two health professionals (CKS, ML), a methodologist (CHMvE) and two language experts participated. During this meeting all versions of questionnaires (T1, T2, T-12, BT1, BT2) were combined and consensus on semantic, idiomatic, experiential and conceptual equivalence was reached resulting in a prefinal version of the questionnaire. The developers of the original questionnaire approved all previous steps and the final version. Finally, the pre-final version was presented in a group of 33 patients (20 women and 13 men; age (SD): 63 (13) years) to explore the clarity of the questionnaire. All patients were asked whether they understood the items and whether they could interpret the questionnaires correctly. Also, the time needed to complete the questionnaire was timed. The findings were discussed among the translators, resulting in only minor changes to the final Dutch version of the LEFS. Mean completion time was $3.5(\mathrm{SD}=1.5)$ minutes. For the final version of the Dutch LEFS see Appendix 1.

\section{Patients and procedure}

Individuals ( $\geq 18$ years) diagnosed with hip or knee osteoarthritis (inclusion period June till October 2009) by an orthopaedic surgeon in the Sint Maartenskliniek hospital Nijmegen were eligible. People reporting concurrent rheumatoid arthritis, fibromyalgia or psoriatic arthritis, were excluded. Written materials were sent by mail: this included an information letter, an informed consent form, the questionnaires and a return envelope. At baseline, all patients completed four questionnaires, the LEFS, the HOOS or KOOS (depending on index joint), the SF-36 and the Hospital Anxiety and Depression Scale (HADS). A reminder was sent to those patients who did not respond within three weeks, to ensure a high response rate. One-hundred and twenty participants were sent a followup questionnaire to evaluate test-retest reliability (within 3 weeks) and another 120 participants were sent a followup questionnaire to evaluate responsiveness (after 3 months); as 100 participants were deemed sufficient [13]. By use of random numbers the 240 patients were selected to either the reliability or responsiveness study. Both follow-up mailings consisted of three questionnaires (LEFS, HOOS or KOOS, and the SF-36) and a global perceived effect question. For test-retest reliability, we considered a time interval of 3 weeks to be appropriate for the current population. For responsiveness, we deemed a period up to 3 months long enough to allow for improvement and brief enough to minimize the risk of a response shift $[18,19]$. 
The study was approved by the Institutional Review Board of the University Medical Centre Nijmegen (ID: 2009/20).

\section{Measures}

The LEFS is a 20-item condition-specific questionnaire designed to be applicable to individuals with musculoskeletal conditions of the lower extremity [12]. Each item of the LEFS scores on a 5-point scale ranging from 0 to 4 points. When scoring the LEFS, up to 4 missing item responses are permitted, for more detailed information see Stratford et al. (2005) [20]. Accordingly, LEFS scores range from 0 to 80 points, with higher scores representing higher levels of functioning.

The HOOS and the KOOS include five subscales: Pain, other Symptoms, Function in Daily living (ADL), Function in Sport and Recreation (Sport/Rec), and hip/kneerelated quality of life (QoL). Standardized response options are given (5-point Likert scale) and each question is scored from 0 to 4 points. Subsequently, a normalized score (100 indicating no symptoms and 0 indicating extreme symptoms) is calculated for each subscale. The Dutch HOOS and KOOS have good internal consistency, construct validity, no floor and ceiling effects and have been found to be reliable [10,11]. Both the HOOS and KOOS questionnaires include the WOMAC osteoarthritis-index in its complete and original format (with permission, www.koos.nu).

The SF-36 is a generic health status questionnaire which contains 36 items [21]. It measures eight major attributes (bodily pain; physical function; social function; role limitations because of physical problems; role limitations because of emotional problems; mental health; vitality; general health perceptions). It is widely used, reliable, validated into Dutch and is easy to complete. Higher scores indicate better health [22].

The Hospital Anxiety and Depression Scale (HADS) is a 14-item scale designed to detect anxiety and depression, independent of somatic symptoms [23]. It consists of two 7-item subscales measuring depression and anxiety on a 4-point response scale (from 0, no symptoms, to 3, maximum symptoms), with possible scores for each subscale ranging from 0 to 21 . HADS is a valid and reliable screening instrument for detecting mood disorder in people with osteoarthritis [24,25]. Higher scores indicate higher levels of disorder.

Fatigue is measured with the 8-itemed "Subjective Fatigue" subscale of the Checklist Individual Strength (CIS) [26]. The outcomes per question are given in a 7-point scale, ranging from the statement 'totally right' to the statement 'totally wrong'. The total score is counted in points with a range of 1-7 per question and a total score range of 8-56 points. The CIS is a sensitive instrument with good discriminating power and reliability [26].
The external criterion for distinguishing between improved and unimproved subjects was a 7-point global perceived effect (GPE) scale. The categories of improvement included the following: completely recovered, much improved, slightly improved, not changed, slightly worse, much worse, and vastly worsened.

\section{Statistical analyses}

Descriptive statistics were used to describe the study population and the number of missing values. Data symmetry was tested by use of visual inspection of the data distribution plotted by histograms. Psychometric qualities of the LEFS were expressed by floor- and ceiling effects, internal consistency, test-retest reliability, minimally detectable change, construct validity, discriminant validity and responsiveness.

\section{Floor and ceiling effects}

Floor and ceiling effects were determined by calculating the number of individuals that obtained the lowest $(0)$ or highest (80) scores possible and were considered present if more than $15 \%$ of the participants achieved the highest or lowest score [27].

\section{Internal consistency and dimensionality}

Internal consistency - an indicator for the homogeneity of a questionnaire - was assessed with Cronbach's alpha and 95\% confidence intervals (95\% CI's). Internal consistency is considered good when Cronbach's alpha lies between 0.7 and 0.9 [28]. Dimensionality was assessed by performing principal component factor analysis with loading coefficient absolute value suppression at 0.40 on the LEFS, KOOS-PF and HOOS-PF to determine if the individual items loaded on a single factor. Factor extraction had three requirements: scree plot point of inflection at the second Eigenvalue, Eigenvalue cut-off $>1.0$, and $\geq 10 \%$ variance [29].

\section{Reliability and minimal detectable change}

Reliability concerns the degree to which the results of measurement are consistent across repeated measurements [28]. Test-retest reliability of the Dutch LEFS was determined by means of Intraclass Correlation Coefficients (ICCs) (two-way random effects model absolute agreement) and Bland and Altman plots [30]. The ICC $(2,1)$ equals variance between patients divided by variance between patients plus variance between measurements plus error variance. The value of the ICC ranges from 0 to 1 , where one represents perfect reliability of the measurement. Consequently, to quantify the reliability of the LEFS scores we determined the standard error of measurement $(\mathrm{SEM}=\mathrm{SD}[\sqrt{ } 1-\mathrm{ICC}])$. The SEM is a representation of measurement error expressed in the same units as the original measurement. We quantified the 
minimal detectable change at the 90\% and 95\% confidence level $\left(\mathrm{MDC}_{90}\right.$ and $\left.\mathrm{MDC}_{95}\right)$ by multiplying the point estimate of the SEM, the square root of 2 (to account for the error associated with repeated measurements), and the $\mathrm{z}$ score of 1.65 or 1.96 (resp. $90 \%$ or $95 \%$ confidence level); formula $\mathrm{MDC}_{90}=\mathrm{SEM} * 1.65 *$ $\sqrt{2}$ and $\mathrm{MDC}_{95}=\mathrm{SEM} * 1.96 * \sqrt{2}[31]$.

\section{Validity}

Construct validity reflects the extent to which a particular measure consistently relates to other measures with theoretically derived hypotheses for the constructs that are being measured [28]. To evaluate the construct validity of the LEFS, we formulated a set of 16 hypotheses (eight for knee osteoarthritis and eight for hip osteoarthritis) about the expected magnitude and direction of relationships between the LEFS and other instruments. If $75 \%$ or more of the arbitrarily set number of 16 hypotheses were confirmed we defined the construct validity of the LEFS as good [32,33].

Discriminant validity was examined for the LEFS and the physical function subscale of the HOOS and KOOS, by contrasting its correlation with the PF subscale of the SF36 with its correlation with the bodily pain subscale of the SF-36. Meng et al's test for dependent data was used to evaluate the differences between those correlations [34].

\section{Responsiveness}

We studied the responsiveness of the LEFS and the WOMAC-PF extracted from the HOOS-PF and KOOS$\mathrm{PF}$ ) in a combined hip and knee group, as only a very small number of patients reported clinically important change, thus not allowing to study the responsiveness of the HOOS and KOOS separately. As yet, a variety of responsiveness statistics is available. However, it is not yet known which of these statistics is better for assessing responsiveness [35] we utilized three different analyses. First we determined the Responsiveness Ratio of Guyatt (GRI: average change of recovered patients (GPE $=1-2)$ / $\mathrm{SD}$ of average change of stable patients $(\mathrm{GPE}=3-5))$. If the responsiveness ratio is larger than 1 , the mean change score in clinically improved patients exceeds the measurement error and the instrument may be considered to be responsive, to an extent that is proportional to the magnitude of the responsiveness ratio [36,37]. Second, we determined the Standardized Response Mean (SRM: average score change/SD of score change). By use of the modified Jackknife testing, we assessed differences in SRM statistically [38]. Third, we calculated Receiver operating characteristic curves (ROC) for the improved subjects and for the worsened subjects using the change scores of the questionnaires and the patients' ratings of change [39]. The patients' rating of change was dichotomized to identify those subjects who experienced a clinically meaningful reduction of symptoms. Important change was defined as 'Much Improvement $(\mathrm{GPE}=1-2)$ ' or 'Much Decline (GPE =6-7)'. Consequently, we computed the area under the curve (AUC). An AUC of 1.0 indicates perfect discrimination, whereas an AUC of 0.50 indicates no performance better than chance.

\section{Results}

Four-hundred and one individuals returned the baseline questionnaire in the study (response rate $82 \%$ ). After the baseline questionnaire, 121 participants received a follow-up mailing to evaluate test-retest reliability (106 responded (88\%)) and 125 participants received a followup mailing to evaluate the responsiveness (112 responded (90\%)). Patient characteristics at baseline and follow-up are presented in Table 1.

The majority of patients (86\%) had less than three missing values. The proportion of missing values in the LEFS questionnaire (4\%) was slightly less than the proportion of missing values in the KOOS (5\%) and the HOOS (8\%) questionnaires. The item 'getting in or out of bath' had the highest number of missing values in each of the questionnaires; $5 \%$ in the HOOS, $7 \%$ in the LEFS and $10 \%$ in the KOOS.

\section{Floor and ceiling effects}

None of the 401 participants reported the lowest possible score whereas one patient $(0.26 \%)$ reported the highest functional level implying that the Dutch LEFS has no floor or ceiling effects. In addition, the distribution of the LEFS was symmetrical.

\section{Internal validity and factoral structure}

The internal consistency for the total group of patients $(\mathrm{n}=401)$ reached a Cronbach's alpha of 0.96 (lower limit (LL) 95\%-CI: 0.95) for the 20 items. For the hip and knee osteoarthritis group Cronbach's alpha reached 0.97 (LL 95\%-CI: 0.96) and 0.95 (LL 95\%-CI: 0.94), respectively. Within-scale principal component factor analysis revealed that all items included in the LEFS, KOOS-PF and HOOS-PF loaded on a single major factor (Table 2).

\section{Reliability and minimal detectable change}

Within three weeks after the baseline questionnaire, five individuals improved (5\%) (GPE $=1-2)$, three worsened $(3 \%)(\mathrm{GPE}=6-7)$ and the majority $(92 \%)$ remained stable $(\mathrm{GPE}=3-5)$. Two-way random effects ANOVA demonstrated that the ICC of the Dutch LEFS questionnaire for the total group $(n=106)$ was 0.86 . For the knee group $(n=81)$ and the hip group $(n=25)$ the ICC was 0.87 and 0.78 , respectively. The standard error of measurement was 4.4 points. The $\mathrm{MDC}_{90}$ and $\mathrm{MDC}_{95}$ of the 
Table 1 Patient and disease characteristics at baseline from the total group and the follow-up data from the reliability and the responsiveness sample*

\begin{tabular}{|c|c|c|c|c|c|c|}
\hline \multirow[t]{2}{*}{$N$} & \multicolumn{2}{|c|}{ Baseline sample } & \multicolumn{2}{|c|}{ Reliability sample ( $\leq 3$ weeks) } & \multicolumn{2}{|c|}{ Responsiveness sample ( $\geq 3$ months) } \\
\hline & \multicolumn{2}{|c|}{401} & \multicolumn{2}{|c|}{106} & \multicolumn{2}{|c|}{112} \\
\hline Age, mean (SD) & \multicolumn{2}{|l|}{$58(13)$} & \multicolumn{2}{|l|}{$61(11)$} & \multicolumn{2}{|l|}{$58(11)$} \\
\hline Female, $+\%$ & \multicolumn{2}{|l|}{$231(58 \%)$} & \multicolumn{2}{|l|}{$65(63 \%)$} & \multicolumn{2}{|l|}{$59(54 \%)$} \\
\hline Index joint, knee & \multicolumn{2}{|l|}{$284(71 \%)$} & \multicolumn{2}{|l|}{$81(76 \%)$} & \multicolumn{2}{|l|}{$81(72 \%)$} \\
\hline BMI, median (IQR) & \multicolumn{2}{|l|}{$26(24-29)$} & \multicolumn{2}{|l|}{$26(24-30)$} & \multicolumn{2}{|l|}{$27(24-30)$} \\
\hline Education, higher ${ }^{\dagger}$ & \multicolumn{2}{|l|}{$77(20 \%)$} & \multicolumn{2}{|l|}{$25(25 \%)$} & \multicolumn{2}{|l|}{$27(25 \%)$} \\
\hline 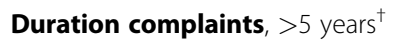 & \multicolumn{2}{|l|}{$144(61 \%)$} & \multicolumn{2}{|l|}{$72(63 \%)$} & \multicolumn{2}{|l|}{$59(58 \%)$} \\
\hline \multirow[t]{3}{*}{ Co-morbidities, yes } & $192(52 \%)$ & & $52(50 \%)$ & & $63(72 \%)$ & \\
\hline & \multicolumn{2}{|c|}{ Baseline data } & \multicolumn{4}{|c|}{ Follow-up data } \\
\hline & Hip group & Knee Group & Hip group & Knee Group & Hip group & Knee Group \\
\hline$N$ & 117 & 284 & 25 & 81 & 31 & 81 \\
\hline LEFS & $36.0(16.6)$ & $39.6(14.1)$ & $29.8(13.5)$ & $36.4(13.7)$ & $34.3(17.0)$ & $37.5(15.0)$ \\
\hline \multicolumn{7}{|l|}{ HOOS/KOOS } \\
\hline Pain, mean (SD) & $44.6(21.3)$ & $49.9(20.0)$ & $41.7(21.1)$ & $46.5(19.7)$ & $43.6(23.7)$ & $53.8(19.3)$ \\
\hline Symptoms, mean (SD) & $41.6(21.4)$ & $54.6(19.3)$ & $40.2(20.3)$ & $52.5(20.5)$ & $39.7(23.5)$ & $55.8(19.6)$ \\
\hline Function, daily living, mean (SD) & $47.5(21.9)$ & $56.5(21.7)$ & $43.8(21.0)$ & $54.2(20.3)$ & $46.5(24.0)$ & $57.8(21.4)$ \\
\hline $\begin{array}{l}\text { Function, sports and recreation, } \\
\text { median (IQR) }\end{array}$ & $25(6-38)$ & $10(0-30)$ & $13(6-25)$ & $5(0-25)$ & $19(6-31)$ & $10(0-25)$ \\
\hline Quality of life, median (IQR) & $25(13-38)$ & $25(13-44)$ & $31(19-38)$ & $25(13-38)$ & $25(13-38)$ & $31(19-44)$ \\
\hline \multicolumn{7}{|l|}{ SF36 } \\
\hline Pain, mean (SD) & $35.6(8.9)$ & $37.3(8.2)$ & $35.6(6.5)$ & $38.6(7.3)$ & $37.0(8.0)$ & $39.9(8.3)$ \\
\hline Functioning, mean (SD) & $31.8(9.8)$ & $32.8(9.2)$ & $29.8(8.5)$ & $32.5(8.2)$ & $31.0(10.0)$ & $33.4(9.5)$ \\
\hline HADS (total), median (IQR) & $9(5-16)$ & $9(4-15)$ & $\mathrm{N} / \mathrm{A}$ & $\mathrm{N} / \mathrm{A}$ & N/A & $\mathrm{N} / \mathrm{A}$ \\
\hline CIS, mean (SD) & $34.8(12.6)$ & $31.0(13.6)$ & N/A & N/A & N/A & N/A \\
\hline
\end{tabular}

* Figures are numbers and percentages in the brackets unless indicated differently. ${ }^{\dagger}$ Cut-off arbitrarily chosen. Abbreviations: BMI = Body Mass Index, IQR $=$ Inter Quartile Range, SD = Standard Deviation.

Table 2 Factor Analysis: Variance Explained for the LEFS, KOOS and HOOS*

\begin{tabular}{lccc}
\hline Factor & \multicolumn{3}{c}{ Initial Eigenvalues } \\
\cline { 2 - 4 } & Total & \% of variance & Cumulative \% \\
\hline LEFS & & 54.18 & 54.18 \\
Factor 1 & 10.84 & 9.33 & 63.51 \\
Factor 2 & 1.87 & 36.49 & 100.00 \\
Factor 3-20 & $0.96-0.06$ & & 57.42 \\
KOOS & & 57.42 & 66.03 \\
Factor 1 & 9.76 & 8.61 & 100.00 \\
Factor 2 & 1.46 & 33.97 & \\
Factor 3-17 & $0.86-0.05$ & & 57.01 \\
HOOS & & 57.01 & 65.84 \\
Factor 1 & 9.69 & 8.83 & 71.82 \\
Factor 2 & 1.50 & 5.98 & 100.00 \\
Factor 3 & 1.02 & 28.18 & \\
Factor 4 & $0.94-0.07$ & & \\
\hline A principal compon & & & \\
\hline
\end{tabular}

* A principal component factor analysis with loading coefficient absolute value suppression at 0.40 .
LEFS questionnaire was 10 points and 12 points, respectively.

The Bland-Altman plot (Figure 1) shows that the mean difference between the two applications of the LEFS was 1.87 points (95\%-CI 0.22 to 3.52 ). The limits of agreement (mean $\pm 1.96 \mathrm{SD}$ ) ranged from -11.56 to 15.30 points.

\section{Validity}

Thirteen of the 16 predefined hypotheses to determine the construct validity were confirmed (81\%) (Tables 3 and 4). The following three hypotheses could not be confirmed. In the hip group we found a correlation of 0.55 between LEFS and CIS scores, which was higher than the predefined cut-off of 0.5. In the knee group we found that the duration of complaints did not influence the LEFS scores and that education level (primary, secondary or higher education) did influence the LEFS scores.

Meng et al's test demonstrated that the association of the LEFS with the SF-36 subscale pain differed significantly with the SF-36 subscale physical functioning 


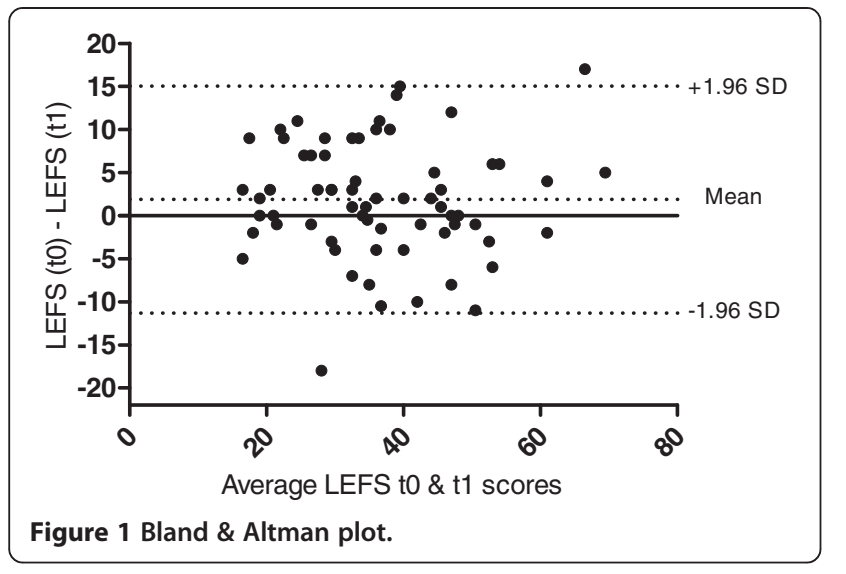

(Table 4), indicating that the LEFS has discriminant validity for pain $(p<0.01)$. We found no significant differences between the association with SF-36 subscale's pain and physical functioning and the HOOS-PF $(\mathrm{r}(95 \%-\mathrm{CI})=0.64$ $(0.51-0.74)$ and $0.71(0.60-0.79), p=0.21)$ and the KOOS-PF $(0.69(0.62-0.75)$ and $0.73(0.67-0.79)$, $p=0.20$, respectively), indicating that both questionnaires do not discriminate between pain and physical functioning.

Table 3 Predefined hypotheses and the confirmation or rejection of the hypotheses for hip OA $(n=117)$ and knee $O A(n=284)$

\begin{tabular}{lll}
\hline & Hip OA & Knee OA \\
\hline $\begin{array}{l}\text { There is a moderate correlation }(r>0.6) \\
\text { between LEFS scores and HOOS/KOOS-PF } \\
\text { subscale. }\end{array}$ & Yes & Yes \\
\end{tabular}

\section{The correlation between the LEFS and the} HOOS/KOOS-PF subscale is higher than

the correlation between the LEFS

and the other subscales of the $\mathrm{HOOS} / \mathrm{KOOS}$

The correlation between LEFS and HADS scores is low $(r<0.5)$.

The correlation between LEFS and CIS scores is low $(r<0.5)$.

Patients with multiple painful lower limb joints demonstrate lower LEFS scores than patients with pain in a single joint.

Patients with complaints less than 5 years demonstrate higher LEFS scores than patients with complaints over 5 years.

The participants' education level (primary, secondary or higher education) does not influence the LEFS scores.

Sociodemographic characteristics, such as sex, doing volunteer work, income, type of health insurance, and family status, are unrelated $(r<0.2)$ to the LEFS score:

Yes Yes

$\begin{array}{ll}\text { Yes } & \text { Yes } \\ \text { No } & \text { Yes } \\ \text { Yes } & \text { Yes } \\ \end{array}$

Yes $\quad$ No

Yes No

Yes

$$
\text { Yes }
$$

$7 / 8(88 \%)$

6/8 (75\%)

Abbreviations: $\mathrm{CIS}=$ Checklist Individuals Strength, HADS = Hospital Anxiety and Depression Questionnaire, HOOS = Hip Osteoarthritis and Outcome Score, KOOS $=$ Knee Osteoarthritis and Outcome Score, LEFS = Lower Extremity Functional Scale, $\mathrm{OA}=$ osteoarthritis, $\mathrm{PF}=$ physical function.

\section{Responsiveness}

Seven people (7\%) reported relevant improvements in function $(\mathrm{GPE}=1-2)$, nine people reported relevant worsening $(8 \%)(\mathrm{GPE}=6-7)$ and the majority remained stable $(85 \%)$ $(\mathrm{GPE}=3-5)$. Responsiveness Ratio of the LEFS was 1.49, close to the outcomes of WOMAC-PF (1.20) and SF36-PF (1.22) (Table 5). Modified Jackknife testing demonstrated no statistical differences between the SRM for the LEFS (0.13) compared with the SRM of the WOMAC (SRM = $0.02, \mathrm{p}=0.45)$ and SF-36 $(\mathrm{SRM}=0.00, \mathrm{p}=0.36)$. ROC curve analysis revealed that for improved patients the AUC was 0.76 (95\% CI: 0.49 - 1.00) for the LEFS, 0.71 (95\% CI: $0.45-0.98$ ) for the WOMAC-PF (extracted from the HOOS-PF and KOOS-PF) and $0.68(0.44-0.93)$ for the SF36-PF. For worsened patients the AUC was 0.63 (95\% CI: $0.42-0.83)$ for the LEFS, $0.56(0.34-0.78)$ for the WOMAC-PF and $0.56(0.35-0.78)$ for the SF36-PF.

\section{Discussion}

The primary objective of this study was to create a reliable and valid Dutch version of LEFS by translation and adaptation. No difficulties were encountered in the translation phase of the study; the structure of the original LEFS was not altered and all items were maintained. Moreover, participants reported no problems in the administration of the questionnaire. Considering the results of this validation study, we deemed the Dutch

Table 4 Correlation data for the hip $O A(n=117)$ and knee $O A(n=284)$ groups at baseline

\begin{tabular}{|c|c|c|}
\hline & \multicolumn{2}{|c|}{ Correlation with LEFS } \\
\hline & Hip group & Knee group \\
\hline & $r(95 \%-\mathrm{Cl})$ & $r(95 \%-\mathrm{Cl})$ \\
\hline \multicolumn{3}{|l|}{ HOOS/KOOS } \\
\hline Pain & $0.71(0.60-0.79)$ & $0.65(0.58-0.72)$ \\
\hline Symptoms & $0.56(0.41-0.67)$ & $0.42(0.32-0.52)$ \\
\hline Function, daily living & $0.78(0.69-0.84)$ & $0.78(0.73-0.83)$ \\
\hline $\begin{array}{l}\text { Function, sports and } \\
\text { recreation }\end{array}$ & $0.74(0.64-0.82)$ & $0.63(0.55-0.70)$ \\
\hline Quality of life & $0.72(0.62-0.80)$ & $0.60(0.52-0.67)$ \\
\hline \multicolumn{3}{|l|}{ SF36 } \\
\hline Pain & $0.51(0.35-0.64)$ & $0.66(0.59-0.72)$ \\
\hline Functioning & $0.82(0.75-0.88)$ & $0.81(0.77-0.85)$ \\
\hline \multicolumn{3}{|l|}{ HADS } \\
\hline Anxiety & $-0.25^{\dagger}(-0.42--0.07)$ & $-0.10(-0.22-0.02)$ \\
\hline Depression & $-0.30^{\dagger}(-0.46--0.12)$ & $-0.28(-0.38--0.16)$ \\
\hline CIS & $-0.55^{\dagger}(-0.67--0.41)$ & $-0.47(-0.56--0.37)$ \\
\hline
\end{tabular}

${ }^{\dagger}$ Due to the inverted scales, the correct interpretation of negative associations is that more anxiety/depression/fatigue is associated with worse function. Abbreviations: $\mathrm{ClS}=$ Checklist Individuals Strength, HADS = Hospital Anxiety and Depression Questionnaire, HOOS = Hip Osteoarthritis and Outcome Score, $\mathrm{IQR}=$ Inter-quartile range, $\mathrm{KOOS}=$ Knee Osteoarthritis and Outcome Score, LEFS $=$ Lower Extremity Functional Scale, OA = osteoarthritis. 
Table 5 Responsiveness ratio (GRI)

\begin{tabular}{lcccccc}
\hline & $\begin{array}{l}\text { Mean } \\
\text { change }\end{array}$ & $\begin{array}{l}\text { SD } \\
\text { (baseline) }\end{array}$ & SD (change) & $\begin{array}{l}\text { Mean change } \\
\text { (GPE = 1-2) }\end{array}$ & $\begin{array}{l}\text { SD mean change } \\
\text { (GPE = 3-5) }\end{array}$ & SRM \\
\hline LEFS & 1.42 & 14.41 & 11.25 & 12.50 & 8.38 & 0.13 \\
WOMAC-PF & 0.19 & 14.84 & 8.86 & 9.66 & 8.06 & 1.49 \\
SF36-PF & 0.00 & 22.73 & 13.68 & 14.44 & 11.86 & 0.02 \\
\hline
\end{tabular}

Abbreviations: GPE = Global perceived effect, GRI = Guyatt Responder Ratio, LEFS = Lower Extremity Functional Scale, SD = Standard Deviation, SF-36-PF = Short Form 36 - Physical Function scale, SRM = Standardized Response Mean, WOMAC = Western Ontario and McMasters University Osteoarthritis Index - Physical Function scale.

version of the LEFS to be an internally consistent, unidimesional, highly reliable and valid questionnaire to determine lower extremity functioning in patients with hip or knee osteoarthritis. Finally, the LEFS revealed good responsiveness by detecting improvement in patient GPE; however this finding should be interpreted with caution, given the small proportion of patient to actually report clinically relevant functional improvement. For our secondary objective, we were unable to demonstrate that the HOOS-PF and KOOS-PF subscales are able to discriminate between pain and physical function.

Construct validity of the Dutch version of the LEFS was good as most of the pre-formulated hypotheses were met. Three of the 16 hypotheses could however not be confirmed. First, in the hip group, the correlation between the lower extremity functioning (LEFS) and fatigue (CIS) was over 0.5 in the hip group, however similar correlations were found for HOOS-PF $(r=0.55)$ and SF-36 PF $(r=0.50)$. As comparative measures also demonstrate such a relation, fatigue might have a stronger relation with functioning than previously thought $[10,15]$. An important difference with previous studies is that we investigated fatigue with a fatigue-specific questionnaire in contrast to others that used the vitality scale of the SF-36 $[10,15]$. Second, participants with knee symptoms for less than five years did not report significantly less symptoms than patients with symptoms for over 5 years. Again this finding was also found for the KOOS-PF $(p=0.90)$ and the SF-36 PF $(p=0.75)$. These findings, could however, be biased by a phenomenon called response shift, which could have resulted in an underreporting of functional disabilities in the group with the longest duration of complaints [40]. Third and final, in the knee group we found that participants' education level (primary, secondary or higher education) did influence the LEFS scores. It would be undesirable if LEFS scores were influenced by education level, as this would indicate that the LEFS is difficult to interpret. Further scrutiny of this finding indicates that patients with knee symptoms who enjoyed a higher education reported less symptoms than patients without or only primary education $(p=0.02)$; also when adjusted for age, sex, BMI, co-morbidities, duration of complaints and being employed. Yet again, this finding was also found for the KOOS-PF $(p=0.04)$, but not for the SF-36 PF subscale $(p=0.08)$. Our findings are in contrast to a previous study that addressed the relation between the LEFS scores (Italian version) and education levels. This discrepancy can possibly explained by the different format of the Italian version; an interview-format instead of a self-reported questionnaire [15]. It would be of interest to further elucidate this relation in other studies.

Although the responsiveness of the Dutch LEFS was good and superior to the WOMAC-PF and SF36-PF, compared to Italian validation study by Cacchio et al. (2010) (AUC= $0.86)$ it was somewhat low [15]. On the other hand, the psychometric properties of the Dutch LEFS (i.e. Cronbach's alpha $[12,15]$, reproducibility $[12,13,15]$ and validity $[12,13])$ were comparable to the findings of previous validation studies. Our results regarding the responsiveness of the LEFS, WOMAC-PF and SF36-PF, should be interpreted with caution. Given the small number of patients reporting clinically relevant change which may have impacted for example the magnitude of the SRM, the point estimates might be spurious. Future (intervention) studies should further investigate the responsiveness of the Dutch LEFS.

The lack of discriminant validity for the WOMAC-PF has been demonstrated in numerous occasions [6-9,41,42]. Therefore, the greater discriminant validity of the LEFS compared to the WOMAC-PF $[13,14]$ was one of the foremost reasons to translate and adapt the LEFS to the Dutch language. In our study we compared the LEFS questionnaire to the HOOS-PF and KOOS-PF subscales. As the physical function subscale of the HOOS and KOOS are very similar to the WOMAC-PF, these subscales are also at great risk for lacking discriminant validity. Our results indicate that the LEFS, but not the KOOS-PF and the HOOS-PF, could discriminate from pain measures, that is, KOOS-PF and HOOS-PF did not show a statistically higher correlation with the PF subscale than with the bodily pain subscale of the SF-36, whereas the LEFS did. As far as we know, we are the first to also demonstrate the lack of discriminant validity in the (Dutch version of the) HOOS and KOOS subscales, as in those particular validation studies only SF-36 subscales other than the bodily pain subscale were examined $[10,11,16]$.

A limitation of our study is that we recruited only individuals with hip and knee osteoarthritis. Originally the LEFS has been developed as a measure that could be used for all kinds of conditions of the lower extremity [12]. The exclusion of other condition hampers the 
generalizability of our findings to other complaints of the lower extremity. We did however evaluate the LEFS ability to differentiate between patients with and without additional lower extremity pain co-morbidities, which demonstrated a linear association between the number of lower extremity joint pain co-morbidities and LEFS scores. The latter analysis showed promise that the Dutch version of the LEFS is also able to detect functional disabilities in patients with other symptoms than just hip and knee osteoarthritis. Another limitation of this study is that we did not assess the association between the Dutch version of the LEFS and a set of performance measures to determine the convergent validity. Future studies should investigate this association. A third limitation, the Cronbach's Alpha value surpassed the cut-off value of 0.90 indicating item redundancy. However, due to the magnitude of our study sample and relatively high number of items this figure might have been inflated [43]. Finally, we studied the construct validity of the LEFS by testing hypotheses according to prespecified cut-off values; however cut-off value are often too rigid by their dichotomous (true/false) nature. Future studies should consider using the lower or upper bound of the $95 \%$ confidence interval of an association.

\section{Conclusions}

We found that the Dutch version of the LEFS has no floor and ceiling effects, good internal consistency, reliability, construct validity and responsiveness. Moreover, the Dutch LEFS demonstrated discriminant validity for pain, as it was able to discriminate between pain and physical functioning, whereas both the HOOS-PF and KOOS-PF did not. Therefore, we recommend the use of the Dutch LEFS as an outcome measure for physical functioning in patients with hip and/or knee osteoarthritis.

\section{Appendix A. Dutch version of LEFS}

Beste meneer/mevrouw,

Heeft $u$ of zou $u$ vandaag enige moeite hebben met de volgende bezigheden?

\begin{tabular}{|c|c|c|c|c|c|c|}
\hline & & $\begin{array}{l}\text { Onmogelijk, } \\
\text { of heel veel } \\
\text { moeite }\end{array}$ & $\begin{array}{l}\text { Veel } \\
\text { moeite }\end{array}$ & Moeite & $\begin{array}{l}\text { Een beetje } \\
\text { moeite }\end{array}$ & $\begin{array}{l}\text { Geen } \\
\text { moeite }\end{array}$ \\
\hline 1. & $\begin{array}{l}\text { een aspect van uw gebruikelijke } \\
\text { werk, huishouden of } \\
\text { schoolactiviteiten }\end{array}$ & 0 & 1 & 2 & 3 & 4 \\
\hline 2. & $\begin{array}{l}\text { uw gebruikelijke hobby's, } \\
\text { vrijetijdsbesteding of } \\
\text { sportactiviteiten }\end{array}$ & 0 & 1 & 2 & 3 & 4 \\
\hline 3. & in of uit bad stappen & 0 & 1 & 2 & 3 & 4 \\
\hline 4. & lopen binnenshuis & 0 & 1 & 2 & 3 & 4 \\
\hline 5. & uw schoenen of sokken aantrekken & 0 & 1 & 2 & 3 & 4 \\
\hline 6. & hurken & 0 & 1 & 2 & 3 & 4 \\
\hline 7. & $\begin{array}{l}\text { iets van de grond optillen, zoals } \\
\text { een tas met boodschappen }\end{array}$ & 0 & 1 & 2 & 3 & 4 \\
\hline 8. & $\begin{array}{l}\text { lichte taken uitvoeren in en om uw } \\
\text { huis }\end{array}$ & 0 & 1 & 2 & 3 & 4 \\
\hline 9. & $\begin{array}{l}\text { zware taken uitvoeren in en om uw } \\
\text { huis }\end{array}$ & 0 & 1 & 2 & 3 & 4 \\
\hline 10. & in of uit een auto stappen & 0 & 1 & 2 & 3 & 4 \\
\hline 11. & 250 meter lopen & 0 & 1 & 2 & 3 & 4 \\
\hline 12. & anderhalve kilometer lopen & 0 & 1 & 2 & 3 & 4 \\
\hline 13. & $\begin{array}{l}\text { een trap op- of aflopen (ongeveer } \\
10 \text { treden) }\end{array}$ & 0 & 1 & 2 & 3 & 4 \\
\hline 14. & één uur staan & 0 & 1 & 2 & 3 & 4 \\
\hline 15. & één uur zitten & 0 & 1 & 2 & 3 & 4 \\
\hline 16. & hardlopen op een vlakke ondergrond & 0 & 1 & 2 & 3 & 4 \\
\hline 17. & hardlopen op een oneffen ondergrond & 0 & 1 & 2 & 3 & 4 \\
\hline 18. & $\begin{array}{l}\text { tijdens het rennen scherpe bochten } \\
\text { maken }\end{array}$ & 0 & 1 & 2 & 3 & 4 \\
\hline 19. & huppen op het aangedane been & 0 & 1 & 2 & 3 & 4 \\
\hline 20. & omdraaien in bed & 0 & 1 & 2 & 3 & 4 \\
\hline
\end{tabular}


Vult $\mathrm{u}$ alstublieft alle items in, ook wanneer $\mathrm{u}$ de bezigheden niet meer doet.

Score: /80 punten.

\section{Competing interests}

The authors declare that they have no competing interests.

\section{Acknowledgements}

All authors like to acknowledge Patsy Anderson, Debby Kenyon-Jackson, and Vera van Schagen for their contributions in translating and re-translating the Dutch version of the LEFS. We also like to thank Clarinda Kersten-Smit and Monique Limborgh for their contributions during the expert meeting and prof. dr. Paul Stratford for allowing us to translate the questionnaire. And of course we want to thank all who participated in this study.

The grant supporter of this study was the Department of Rheumatology of the Sint Maartenskliniek hospital, Nijmegen, The Netherlands.

\section{Author details}

'Department of Rheumatology, Sint Maartenskliniek, PO Box 9011, Nijmegen 6500 GM, The Netherlands. ${ }^{2}$ Caphri Research School, Maastricht University Medical Centre, Maastricht, The Netherlands. ${ }^{3}$ Department of Epidemiology, Maastricht University Medical Centre, Maastricht, The Netherlands.

\section{Authors' contributions}

Authors TJH, RAdB, AAdB, CHMvdE; 1) have all contributed to conception and design of this study; 2) have been involved in drafting the manuscript and revising it critically for important intellectual content; and 3) have given final approval of this version to be published.

Received: 22 November 2011 Accepted: 2 July 2012

Published: 2 July 2012

\section{References}

1. Veenhof C, Bijlsma JW, van den Ende CH, van Dijk GM, Pisters MF, Dekker J: Psychometric evaluation of osteoarthritis questionnaires: a systematic review of the literature. Arthritis Rheum 2006, 55(3):480-492.

2. Bellamy N: WOMAC osteoarthritis index. A user's guide. London, Ontario, Canada: University of Western Ontario; 1995.

3. Bellamy N, Kirwan J, Boers M, Brooks P, Strand V, Tugwell P, Altman R, Brandt K, Dougados M, Lequesne M: Recommendations for a core set of outcome measures for future phase III clinical trials in knee, hip, and hand osteoarthritis. Consensus development at OMERACT III. J Rheumatol 1997. 24(4):799-802.

4. Hochberg MC, Altman RD, Brandt KD, Moskowitz RW: Design and conduct of clinical trials in osteoarthritis: preliminary recommendations from a task force of the Osteoarthritis Research Society. I Rheumatol 1997, 24(4):792-794.

5. Dworkin RH, Turk DC, Farrar JT, Haythornthwaite JA, Jensen MP, Katz NP Kerns RD, Stucki G, Allen RR, Bellamy N, et al: Core outcome measures for chronic pain clinical trials: IMMPACT recommendations. Pain 2005, 113(1-2):9-19.

6. Soderman P, Malchau H: Validity and reliability of Swedish WOMAC osteoarthritis index: a self-administered disease-specific questionnaire (WOMAC) versus generic instruments (SF-36 and NHP). Acta Orthop Scand 2000, 71(1):39-46.

7. Soderman P, Malchau $\mathrm{H}$ : Is the Harris hip score system useful to study the outcome of total hip replacement? Clin Orthop Relat Res 2001, 384:189-197.

8. Terwee CB, van der Slikke RM, van Lummel RC, Benink RJ, Meijers WG, de Vet HC: Self-reported physical functioning was more influenced by pain than performance-based physical functioning in knee-osteoarthritis patients. J Clin Epidemiol 2006, 59(7):724-731.

9. Escobar A, Quintana JM, Bilbao A, Azkarate J, Guenaga Jl: Validation of the Spanish version of the WOMAC questionnaire for patients with hip or knee osteoarthritis. Western Ontario and McMaster Universities Osteoarthritis Index. Clin Rheumatol 2002, 21(6):466-471.

10. de Groot IB, Reijman M, Terwee CB, Bierma-Zeinstra SM, Favejee M, Roos EM, Verhaar JA: Validation of the Dutch version of the Hip disability and Osteoarthritis Outcome Score. Osteoarthritis Cartilage 2007, 15(1):104-109.
11. de Groot IB, Favejee MM, Reijman M, Verhaar JA, Terwee CB: The Dutch version of the Knee Injury and Osteoarthritis Outcome Score: a validation study. Health Qual Life Outcomes 2008, 6:16.

12. Binkley JM, Stratford PW, Lott SA, Riddle DL: The Lower Extremity Functional Scale (LEFS): scale development, measurement properties, and clinical application. North American Orthopaedic Rehabilitation Research Network. Phys Ther 1999, 79(4):371-383.

13. Pua YH, Cowan SM, Wrigley TV, Bennell KL: The Lower Extremity Functional Scale could be an alternative to the Western Ontario and McMaster Universities Osteoarthritis Index physical function scale. J Clin Epidemiol 2009, 62(10):1103-1111.

14. Stratford PW, Kennedy DM, Hanna SE: Condition-specific Western Ontario McMaster Osteoarthritis Index was not superior to regionspecific Lower Extremity Functional Scale at detecting change. J Clin Epidemiol 2004, 57(10):1025-1032.

15. Cacchio A, De Blasis E, Necozione S, Rosa F, Riddle DL, di Orio F, De Blasis D, Santilli V: The Italian version of the lower extremity functional scale was reliable, valid, and responsive. J Clin Epidemiol 2010, 63(5):550-557.

16. Roos EM, Toksvig-Larsen S: Knee injury and Osteoarthritis Outcome Score (KOOS) - validation and comparison to the WOMAC in total knee replacement. Health Qual Life Outcomes 2003, 1:17.

17. Beaton DE, Bombardier C, Guillemin F, Ferraz MB: Guidelines for the process of cross-cultural adaptation of self-report measures. Spine (Phila Pa 1976) 2000, 25(24):3186-3191.

18. Sprangers MA, Schwartz CE: Integrating response shift into healthrelated quality of life research: a theoretical model. Soc Sci Med 1999, 48(11):1507-1515.

19. Robling M, Hood K: Response shift, responsiveness or recall bias? Br J Gen Pract 2002, 52(480):585.

20. Stratford PW, Hart DL, Binkley JM, Kennedy DM, Alcock GK, Hanna SE: Interpreting Lower Extremity Functional Status Scores. Physiother Can 2005, 57(2):9.

21. Ware JE Jr, Sherbourne CD: The MOS 36-item short-form health survey (SF-36). I. Conceptual framework and item selection. Med Care 1992, 30(6):473-483

22. Aaronson NK, Muller M, Cohen PD, Essink-Bot ML, Fekkes M, Sanderman R, Sprangers MA, te Velde A, Verrips E: Translation, validation, and norming of the Dutch language version of the SF-36 Health Survey in community and chronic disease populations. J Clin Epidemiol 1998, 51(11):1055-1068.

23. Spinhoven P, Ormel J, Sloekers PP, Kempen Gl, Speckens AE, Van Hemert AM: A validation study of the Hospital Anxiety and Depression Scale (HADS) in different groups of Dutch subjects. Psychol Med 1997, 27(2):363-370.

24. Bjelland I, Dahl AA, Haug TT, Neckelmann D: The validity of the Hospita Anxiety and Depression Scale. An updated literature review. J Psychosom Res 2002, 52(2):69-77.

25. Axford J, Butt A, Heron C, Hammond J, Morgan J, Alavi A, Bolton J, Bland M: Prevalence of anxiety and depression in osteoarthritis: use of the Hospital Anxiety and Depression Scale as a screening tool. Clin Rheumatol 2010, 29(11):1277-1283.

26. Vercoulen JH, Swanink CM, Fennis JF, Galama JM, van der Meer JW, Bleijenberg G: Dimensional assessment of chronic fatigue syndrome. $J$ Psychosom Res 1994, 38(5):383-392.

27. McHorney CA, Tarlov AR: Individual-patient monitoring in clinical practice: are available health status surveys adequate? Qual Life Res 1995, 4(4):293-307.

28. Streiner DLN, GR: Measuring change, Responsiveness and sensitivity to change. In Health measurement scales. 4th edition. Edited by Streiner DLN, GR. Oxford, UK: Oxford University Press; 2008:277-288.

29. Gabel CP, Melloh M, Burkett B, Michener LA: Lower limb functional index: development and clinimetric properties. Phys Ther 2012, 92(1):98-110.

30. Bland JM, Altman DG: Statistical methods for assessing agreement between two methods of clinical measurement. Lancet 1986, 1(8476):307-310

31. Donoghue D, Stokes EK: How much change is true change? The minimum detectable change of the Berg Balance Scale in elderly people. J Rehabil Med 2009, 41(5):343-346.

32. Mokkink LB, Terwee CB, Patrick LD, Alonso J, Stratford PW, Knol DL, Bouter LM, De Vet HC: COSMIN-manual 2010.

33. Terwee CB, Bot SD, de Boer MR, van der Windt DA, Knol DL, Dekker J, Bouter $L M$, de Vet HC: Quality criteria were proposed for measurement properties of health status questionnaires. J Clin Epidemiol 2007, 60(1):34-42. 
34. Meng X, Rosenthal R, Rubin DB: Comparing Correlated Correlation Coefficients. Quant Methods Psychol 1992, 111(1):4.

35. Angst $F$ : The new COSMIN guidelines confront traditional concepts of responsiveness. BMC Med Res Methodol 2011, 11:152. author reply 152.

36. Guyatt GH, Kirshner B, Jaeschke R: Measuring health status: what are the necessary measurement properties? J Clin Epidemiol 1992, 45(12):1341-1345.

37. de Vet HC, Bouter LM, Bezemer PD, Beurskens AJ: Reproducibility and responsiveness of evaluative outcome measures. Theoretical considerations illustrated by an empirical example. Int J Technol Assess Health Care 2001, 17(4):479-487.

38. Bessette L, Sangha O, Kuntz KM, Keller RB, Lew RA, Fossel AH, Katz JN: Comparative responsiveness of generic versus disease-specific and weighted versus unweighted health status measures in carpal tunnel syndrome. Med Care 1998, 36(4):491-502.

39. Stratford PW, Binkley FM, Riddle DL: Health status measures: strategies and analytic methods for assessing change scores. Phys Ther 1996 76(10):1109-1123.

40. Schwartz CE, Andresen EM, Nosek MA, Krahn GL: Response shift theory: important implications for measuring quality of life in people with disability. Arch Phys Med Rehabil 2007, 88(4):529-536.

41. Bombardier C, Melfi CA, Paul J, Green R, Hawker G, Wright J, Coyte P: Comparison of a generic and a disease-specific measure of pain and physical function after knee replacement surgery. Med Care 1995, 33(4 Suppl):AS131-AS144.

42. Nilsdotter AK, Lohmander LS, Klassbo M, Roos EM: Hip disability and osteoarthritis outcome score (HOOS)-validity and responsiveness in total hip replacement. BMC Musculoskelet Disord 2003, 4:10.

43. Ponterotto JG, Ruckdeschel DE: An overview of coefficient alpha and a reliability matrix for estimating adequacy of internal consistency coefficients with psychological research measures. Percept Mot Skills 2007, 105(3 Pt 1):997-1014.

doi:10.1186/1471-2474-13-117

Cite this article as: Hoogeboom et al:: The Dutch Lower Extremity

Functional Scale was highly reliable, valid and responsive in individuals

with hip/knee osteoarthritis: a validation study. BMC Musculoskeletal

Disorders 2012 13:117.

\section{Submit your next manuscript to BioMed Central and take full advantage of:}

- Convenient online submission

- Thorough peer review

- No space constraints or color figure charges

- Immediate publication on acceptance

- Inclusion in PubMed, CAS, Scopus and Google Scholar

- Research which is freely available for redistribution 